\title{
EL VIRREY TOLEDO: FIGURA CLAVE PARA LA SUPRESIÓN DE LA AUDIENCIA DE CONCEPCIÓN
}

\author{
THE VICEROY TOLEDO: KEY FIGURE FOR THE SUPPRESSION \\ OF THE AUDIENCIA DE CONCEPCIÓN
}

\author{
Matthias Gloël*
}

\begin{abstract}
Este artículo discute la importancia que tuvo el virrey Francisco de Toledo para la supresión de la Audiencia de Concepción. Se establece la hipótesis que entre las múltiples quejas y recomendaciones de suprimirla, las del virrey resultaron determinantes. Para probar lo anterior dividimos el texto en tres partes principales: primero, un breve recorrido por los ocho años de la existencia de la Audiencia con las circunstancias de su creación y supresión. Segundo, las críticas empleadas por el virrey Toledo y su repetida recomendación de quitar la Audiencia de Concepción. Tercero, los lazos e influencias que tenía el virrey en la corte madrileña que hacían posible que sus recomendaciones fuesen escuchadas. Con ello, se concluye que el peso del virrey fue determinante para que se suprimiera la Audiencia de Concepción.
\end{abstract}

Palabras claves: Historia colonial, historia de Chile, siglo XVI, Felipe II, Francisco de Toledo.

This paper discusses the importance of the viceroy Francisco de Toledo for suppressing the Audiencia de Concepción. We establish the hypothesis that among the multiple complaints and recommendations to suppress it, the viceroy ones were decisive. In order to prove it, we divide the text into three main parts: first, a short résumé about the eight years of its existence, including the circumstances of its establishment and suppression. Second, the criticisms made by the viceroy Toledo and his constant recommendation to cut the Audiencia de Concepción. Third, the viceroy's ties and influence at the court in Madrid, which made it possible that his recommendations found open ears. Finally, we conclude that the viceroys' opinion was decisive for the Audiencia to be shut down. Key words: Colonial history, Chilean history, $16^{\text {th }}$ century, Philip II, Francisco de Toledo.

\section{Introducción $^{1}$}

No hay duda de que existen numerosos estudios, tanto clásicos como actuales, acerca de las audiencias indianas de la Corona española (Arvizu Galarraga 1986; Barrios 2004; Bermúdez 1976; García Gallo 1975; Garriga 1994; 2004; Reig Satorres 1972; Suárez 1989). A pesar de ello, Antonio Dougnac Rodríguez (2004: 578) critica que la mayoría de la bibliografía existente estudia las Audiencias como instituciones estáticas y lamenta un cierto estancamiento en la investigación de estos tribunales. En esta abundancia, por lo menos en cantidad, las audiencias chilenas parecen constituir una excepción. Así lo señala Javier Barrientos Grandón (2003: 235) para el caso de la Audiencia de Santiago de Chile, fundada en 1605 , carencia que principalmente este mismo autor se ha empeñado a remediar (Barrientos Grandón 1990; 1992; 2000; 2003).

Lo mismo se puede afirmar para la Audiencia de Concepción, la primera en Chile que solo existió durante pocos años (1565/15672-1573/1575).
Tradicionalmente no solía contar con estudios pormenorizados al ser considerada como un preludio de la posterior Audiencia de Santiago y así es tratada de forma introductoria (Muñoz Feliú 1937; Salvat Monguillot 1973). Hay que destacar en este sentido el trabajo pionero de Alfonso Urrejola Arrau (1946) que logró, si bien de forma muy breve, individualizar la Audiencia de Concepción. En tiempos relativamente recientes se realizaron estudios más completos (Barrientos Grandón 1993; Martiré 1997; Mazzei de Grazia 1989), los que evidencian un buen manejo de las fuentes para esclarecer muchos aspectos de esta primera audiencia chilena. Durante aquellos años se publicó, además, un corpus documental acerca de dicha audiencia, editado por la Academia Chilena de la Historia (1992).

Como motivos para su rápida supresión dichos estudios suelen destacar las malas relaciones del presidente Melchor Bravo de Saravia con los oidores y con el fiscal, la imposibilidad de administrar justicia en tierras de guerra, los excesivos gastos provocados por la audiencia, la corrupción del

* Universidad Católica de Temuco. Temuco, Chile. Correo electrónico: mgloel@uct.cl 
propio presidente, de hecho, la residencia que se le tomó en 1575 se encuentra llena de acusaciones de ello (Góngora 1951: 62), y la general inutilidad de la audiencia a la hora de administrar justicia. En este artículo no pretendemos negar la existencia de ninguno de estos factores referidos, sin embargo, se suele obviar un factor que creemos fue clave para llegar a tomar la decisión de la supresión: la opinión y actuación del virrey Francisco de Toledo (1569-1581). Trataremos de probar dicha hipótesis mediante las cartas del virrey y una contextualización de su importancia para el gobierno peruano y su posición en la corte madrileña.

\section{La creación de la Audiencia de Concepción}

El virrey y las audiencias han sido considerados los dos pilares de la Corona en los territorios americanos (Merluzzi 2012: 206; Sánchez 1996: 161 entre otros; ver también Rivero Rodríguez 2011). En el momento de la creación de la Audiencia de Concepción, las audiencias en Indias llevaban más de medio siglo de existencia desde la creación del juzgado mayor en Santo Domingo (1511), el que tras la fundación del Consejo de Indias (1524) se convertirían en Audiencia (1526). El motivo principal era sustituir el poder militar de los conquistadores por uno civil, representado por letrados. Lo anterior es válido principalmente a partir de las Leyes Nuevas (1542), ya que desde esa fecha son realmente tribunales supremos (Garriga 2004: 738). Como en tantos otros casos, como los propios virreyes, por ejemplo, se trata de una institución de origen peninsular que se adapta a las circunstancias americanas. Sus orígenes se remontan al siglo XIV durante los reinados de los primeros Trastámara (Garriga 1994). Aproximadamente un siglo después, los Reyes Católicos reorganizan la Audiencia en 1475 y en 1485 emiten las primeras ordenanzas para ella (Dougnac Rodríguez 2004: 543). Como apunta José de la Puente Brunke (2004: 590), en las décadas y siglos siguientes se invocaron los ejemplos de Valladolid y Granada (creada tras la conquista del reino) cuando surgían dudas acerca del funcionamiento de las audiencias indianas.

En América, las audiencias eran la máxima institución en lo jurídico donde sobre todo se podían apelar fallos dictados por jueces inferiores (Hernández Sánchez-Barba 1992: 111; Pietschman 1980: 116). El rey como juez universal era el máximo encargado de la administración de la justicia, por lo que las audiencias ejercían una facultad directa del monarca. Hasta entonces, la audiencia responsable para Chile era la de Lima, ante ella se podían apelar las sentencias del justicia mayor quien constituía la autoridad más alta presente en Chile. Sin embargo, no se trataba todavía de un tribunal sino solamente de una autoridad jurisdiccional unipersonal.

Como veremos ahora, tampoco las circunstancias de la creación de la audiencia chilena están del todo aclaradas por la historiografía existente. Ricardo Ferrando Keun (2012 [1986]: 141) ubica las necesidades de crear una audiencia en las quejas contra el mal gobierno de Pedro de Villagra (1563-1565). Barrientos Grandón (2000: 11), en cambio, detecta las primeras voces que exigen una audiencia para Chile ya para 1561, citando dos cartas del oidor de Charcas Juan de Matienzo al rey, del ocho y trece de abril de 1561, respectivamente. Sin embargo, lo que Matienzo realmente postulaba no era una audiencia para Chile sino una audiencia cuya responsabilidad incluyera a Chile. Así señala en una carta escrita el ocho de abril de 1561 que el lugar idóneo sería Arequipa "que es puerto de mar a lo menos cerca del por estar en medio del peru y chile, a do podría venir todos los negocios de Chile muy fácilmente y los de Tucuman y de los Charcas y del Cuzco" (Levillier 1918: 4). Por tanto, lo que Matienzo pretendía es que se trasladara la Audiencia de Charcas a Arequipa y que se extienda considerablemente su territorio de jurisdicción. En una tercera carta, desatendida por los autores hasta ahora mencionados, propone además absoluta autonomía para dicha audiencia, ya que "ayudaría mas a esto questa audiença tuviese todo el gobierno de su distrito por si sin que virrey ni otra persona se entremetiese en cosa de justicia ny governaçion" (Levillier 1918: 45). Entonces, las propuestas de Matienzo no tienen que ver con las necesidades de Chile sino con la aspiración de pertenecer a una especie de súper audiencia con plenos poderes en justicia y gobierno.

Los primeros documentos que piden una audiencia exclusivamente para Chile parecen ser aproximadamente de 1563 y 1564, los que también refiere Barrientos Grandón (1993: 133). Se trata de una carta del cabildo de Santiago (tres de diciembre de 1563) y otra del licenciado Monzón, oidor de la Audiencia de Lima (24 de abril de 1564), ambas dirigidas al rey. Mazzei de Grazia (1989: 28-29) recoge incluso otra anterior del doce de octubre de 1562 de Rodrigo de Vega Sarmiento, factor de la 
Real Hacienda de Chile, quien señala la necesidad de una audiencia para controlar las rentas reales que en aquel momento las manejaba únicamente el gobernador.

Sin embargo, todos concuerdan en que estas iniciativas no fueron fructíferas y que la persona que finalmente convenció a la corte de la necesidad de una audiencia para Chile fue el licenciado Lope García de Castro (Barrientos Grandón 2000: 13; González Echenique 1992: 12; Martiré 1997: 1381; Mazzei de Grazia 1989: 30), quien desde septiembre 1564 a cargo del gobierno virreinal tras la muerte del virrey conde de $\mathrm{Nieva}^{3}$. Efectivamente, García de Castro durante 1565 envió varias cartas al rey y al Consejo de Indias recomendando quitar la audiencia de Quito y trasladarla a Chile (Levillier 1921: 62-63; 74; 92; 134). No obstante, como apunta el propio Barrientos Grandón (1993: 135), si bien no se ha conservado la real cédula de erección de la Real Audiencia de Concepción, sí se conocen los nombramientos de los oidores, los que se despacharon ya el catorce de enero de 1565. Efectivamente, en el corpus publicado por la Academia Chilena de la Historia (1992: 201-202) se reproducen los nombramientos de Egas Venegas como oidor y Gregorio de Torres como portero de la Audiencia de Concepción. Por tanto, la conclusión a la que arriba Barrientos Grandón es que "las instancias del presidente de la audiencia limeña dieron fruto, pues a principios de 1565, Felipe II decidió la creación de una audiencia real en el reino de Chile" carece de lógica, ya que todas las cartas de García de Castro, el que seguramente todavía no conocía dicha decisión, se enviaron posteriormente. Varios autores señalan una real cédula del 27 de agosto de 1565 que habría erigido la Audiencia de Concepción, sin embargo, ninguno de ellos indica la referencia (Amunátegui 1890: 132; Dougnac Rodríguez 2004: 552; Ferrando Keun 2012 [1986]: 142; Huneeus Pérez 1956: 87; Levillier, 1920: 28). Aunque fuera cierta dicha fecha, parece evidente que en enero de 1565 la decisión acerca de la creación ya estaba tomada, ya que se empezaron a nombrar funcionarios para la Audiencia de Concepción. Con todo, el caso de la Audiencia de Charcas muestra que podía ocurrir que se nombraban los oidores (1559) antes de crear oficialmente la institución (1561). Podemos concluir, entonces, que para la creación de la audiencia la figura del gobernador tuvo menos relevancia de lo que tradicionalmente se ha sostenido.

\section{Críticas a la Audiencia de Concepción}

Dos años después de su erección formal, en 1567 la Audiencia de Concepción finalmente empezó a operar. Junto con hacerse cargo de la justicia, también asumió el gobierno de la gobernación de Chile con el objetivo de poner fin a la guerra contra los llamados araucanos. Tras la muerte del primer gobernador Pedro de Valdivia en 1553 , los españoles no volvieron a lograr someter a los indígenas, lo que llevó a una dinámica de guerra constante.

Como presidente y gobernador se designó a Melchor Bravo Saravia, quien había servido durante muchos años en la Audiencia de Lima y que pocos años antes había salido sin sanciones de la visita que se le hizo a la audiencia limeña y a él personalmente como magistrado (Angeli, 2004). La desilusión llegaría pronto y desde 1569 se empezó a pedir desde distintos ámbitos la supresión de la audiencia (Barrientos Grandón 1993: 169). Las cartas están recogidas en el corpus documental de la Academia Chilena de la Historia y también referidas en los estudios anteriormente mencionados. Lo que se puede señalar al respecto es que dichas peticiones de supresión se suelen presentar como un corpus monolítico sin tomar en cuenta que podría haber motivos distintos en sus respectivos autores. Por ejemplo, en caso de las críticas del fiscal Álvaro García de Navía hacia la audiencia (Barrientos Grandón1993: 169; Mazzei de Grazia 1989: 44) es necesario tener en cuenta la mala relación que este tenía especialmente con el presidente Saravia (Martiré 1997: 1388), es decir, podía haber motivos personales para acabar con la audiencia. Clérigos como fray Lope de la Fuente (Barrientos Grandón 1993), en cambio, debían tener otras razones por quejarse de la audiencia como el hecho que su política de guerra probablemente no era favorable para llevar a cabo la evangelización. Finalmente, por una real cédula del 26 de agosto de 1573 se anunciaba la supresión de la Audiencia de Concepción aludiendo a "la continua guerra y alteración en que esas provincias están y que para su sosiego y quietud y por el mal aparejo que hay para que esa audiencia se pueda sustentar y entretener" (Academia Chilena de la Historia 1992: 183). Para Barrientos Grandón (2000: 19) "parecía reconocerse la opinión de los vecinos en torno a la inutilidad de una real audiencia en un reino que se hallaba aun por conquistar y pacificar". 


\section{El virrey Toledo y la Audiencia de Concepción}

Francisco de Toledo, virrey desde 1569 ha sido relacionado muy poco con la supresión de la Audiencia de Concepción. Barrientos Grandón quien más a fondo ha estudiado las audiencias chilenas, no lo refiere como factor alguno para dicho proceso. Mazzei de Grazia (1989: 86) señala que, si el licenciado Castro fue importante para la erección de la Audiencia de Concepción, Toledo lo fue para su supresión. Sin embargo, el autor, a diferencia de muchas otras partes de su obra, no se respalda en ninguna documentación para sostener esta afirmación ni tampoco explica por qué entre todas las opiniones considera que la del virrey fue la clave para que en la corte se tomara la decisión. Martiré (1997: 1396) es un poco más explícito señalando que "por fin la intervención decidida del virrey Francisco de Toledo volcará la resolución regia en el sentido indicado". A continuación, refiere tres cartas (primero de marzo de 1572, 20 de marzo de 1573, tres de junio de 1573), obviando, no obstante, por una parte, el hecho de que la intervención de Toledo había empezado ya dos años antes como veremos y, por otra parte, tampoco explica por qué sería la opinión de Toledo la que marcaría la diferencia en la corte.

La investigación acerca del virrey Toledo ha tenido un auge en los años recientes (Gómez Rivas 1990; Merluzzi 2003; Mumford 2012; Salles y Noejovich 2008; Tantaleán Arbulú 2011) pero a pesar de los grandes aportes que han hecho estas obras, la relación del virrey con Chile no es tema en ninguna de ellas. Sin embargo, en su calidad de virrey (a diferencia de gobernador, capitán general y presidente de la audiencia) Toledo representaba la dignidad del monarca también en Chile y se han recopilado muchas cartas en las que Toledo toma posición acerca de los acontecimientos en Chile y de las decisiones que hay que tomar (Levillier 1921, 1924; Toribio Medina 1956, 1957). Varias de dichas cartas también se refieren a la Audiencia de Concepción.

Ya el ocho de febrero de 1570, el virrey envía tres largas cartas a Felipe II, en estas se refiere, entre otras muchas temáticas, también a la audiencia chilena. La primera trata de los defectos de gobierno que ha detectado Toledo y acerca de la audiencia expone que "no dudo sino que vuestra magestad entenderá el notable hierro que se hizo en proveer la de chile en tiempo que la tierra no tenia otros negocios sino militares". Recomienda que ese dinero sería mejor invertido en soldados para finalmente poder pacificar aquella tierra (Levillier 1921: 317318). La segunda carta que data del mismo día, trata de medidas que propone el virrey para lograr el buen gobierno. En esta ocasión hace extensa su crítica a la audiencia chilena, también a las de Charcas y Quito, señalando que "gastan a vuestra magestad mucha cantidad de su Real hazienda y la Relaçion que hasta aora he tenido del util que hazen parece harto menos del que promete lo mucho que gastan" (Levillier 1921: 358). En la tercera carta, finalmente, afirma que

el audiencia que a hecho dos efectos el uno perder a vuestra magestad los soldados que llevaron para el socorro y lo que se gasto en hazelle de la real caxa el otro consumir con sus salarios hasta allanallo de paz sin tener otros negocios en que entender el audiencia sino militares no siendo anejas a ellos ni dejándolos a los que lo an tratado (Levillier 1921: 402).

Un año más tarde, en una carta del 25 de marzo de 1571, el virrey se muestra con la misma convicción señalando que "en cuanto quitar el Audiencia y el que gobierna, no me parece que hay duda" (Toribio Medina 1956: 364). Esta carta se envía desde Cuzco, hacia donde había salido Toledo desde Lima en octubre de 1570. El año siguiente de 1572 es el que Toledo más insiste por la supresión de la Audiencia de Concepción. En un informe muy extenso acerca de diversos asuntos de Perú del primero de marzo de 1572 se refiere también a las audiencias señalando que se debería debatir la conveniencia de que existen tantas. En cuanto a la de Concepción se muestra categórico una vez más: "todos convienen en que no solo se podria escusar pero ques y sera dañosa en el entretanto que aquella tierra anduviere en guerra" (Levillier 1924: 205).

En otra carta del mismo día referida a materias de guerra le recuerda al rey que ya se había pronunciado en otras ocasiones al tema. Para mejorar la situación en Chile "vuestra magestad entendio en los despachos que se ynbiaron desde Lima que uno de los rremedios era quitar aquella audiencia" (Levillier 1924: 290). En otra carta más de 1572, de la que no es posible establecer la fecha exacta, en cuanto a la Audiencia de Concepción nuevamente 
remite "a lo que sobre esto tengo escrito en la materia de govierno y en lo de las provincias de chile en la de la guerra" (Levillier 1924: 389).

En las cartas de 1573, si bien Toledo no cambia de postura, sí modifica el enfoque de su argumentación. El 20 de marzo de aquel año señala la incapacidad del presidente de la Audiencia de Concepción, Bravo de Saravia, que "está muy viejo para aquello y aun para otro trabajo". Implícitamente, el virrey sigue recomendando la supresión, ya que entiende que sin Saravia no hay audiencia, por lo que sugiere que los demás oidores se muevan a alguna otra audiencia del Perú (Toribio Medina 1957: 11). También la carta del 3 de junio está principalmente dirigida contra el gobernador Saravia. Señala que incluso si se mantuviera la audiencia, a pesar del "parecer de todos que tantas veces está referido", sugiere al menos "proveer un presidente y gobernadores y capitán general que supiese más de esto que de letras" (Toribio Medina 1957: 15). Como se aprecia, Toledo ve en Saravia más su perfil de abogado que de militar a pesar de que Saravia había participado activamente en la supresión de la rebelión de Hernández Girón en los años 1553-1554. Como ya se ha mencionado, una real cédula del 26 de agosto de 1573 suprime la audiencia chilena, por lo que probablemente esta última carta de junio incluso llegó a la corte después de decretarse dicha supresión. El propio Toledo parece enterarse de ello más de un año después, ya que durante 1574 sigue comunicándose de forma normal con la audiencia chilena (Toribio Medina, 1957: 64-76; 113-125). Solo en una carta del 10 de noviembre le confirma a Felipe II la recepción de dicha información señalando que le parece "muy buen acuerdo el que Vuestra Majestad mandó tomar, así en suspender lo de aquel audiencia" (Toribio Medina, 1957: 131).

\section{El peso de la opinión del virrey Toledo}

Ahora toca responder la justificada pregunta de por qué creemos que entre las tantas opiniones que recomendaban la supresión de la Audiencia de Concepción la de Toledo fue la más importante para que se tomara esta decisión en la corte. Ante todo es preciso señalar que Toledo como virrey representa la máxima autoridad para la gobernación de Chile, al igual que de Panamá, Quito, Charcas entre otros más (Tantaleán Arbulú 2011: 252). Para entender lo anterior es necesario aclarar la distinción entre gobernador y virrey. Se trata de dos oficios distintos que en el caso peruano solían recaer sobre la misma persona, así también en el caso de Toledo. De hecho, Toledo recibe cuatro nombramientos en total, de virrey, gobernador, capitán general y presidente de la audiencia. Los últimos tres son oficios que se limitan territorialmente a los reinos del Perú propiamente dicho. El virrey, en cambio, es menos un oficio que una dignidad (alter ego del monarca), con lo que Toledo representa la dignidad real en todos los territorios que forman el virreinato del Perú. Es admisible agregar que el mandato de Toledo se halla en la tradición de los virreyes del emperador Carlos V (Carlos I en Castilla) que tuvieron mandatos muy largos, antes de que se limitaran los virreinatos a tres años con la posibilidad de una sola renovación ${ }^{4}$.

El propio Toledo fue en cierto sentido un virrey especial, al igual que el virrey Enríquez que casi durante los mismos años lo fue de Nueva España (1568-1580). Ambos fueron nombrados en un momento que la Corona todavía no consideraba lo suficientemente asentado y asegurado en el partido el dominio y la administración en América, especialmente en el caso del Perú. Por ello, siguiendo la tradición de juntas extraordinarias bajo los Reyes Católicos y Carlos V, se convocó en 1568 la llamada Junta Magna (Abril Stoffels 1996; Merluzzi 2007; Ramos 1986). Para Parker (1998: 8) dicha junta sería uno de los ejemplos que evidencia la global strategic vision de Felipe II. Una de sus tareas principales fue encontrar las personas idóneas para la renovación administrativa de las Indias. La importancia de la junta se evidencia también por el hecho de que contra la costumbre el nombramiento de los dos virreyes Toledo y Enríquez en este caso no pasó por el Consejo de Indias. El consejo además había quedado en cierta forma desacreditado por los nombramientos del conde de Nieva para el Perú y el marqués de Falces para Nueva España, dos virreyes que decepcionaron profundamente a la corte (Poole 2004: 130). Entre otros motivos por eso también el Consejo se encontraba bajo visita desde 1567 , realizada por Juan de Ovando y que terminaría solo en 1571 (Hera Pérez-Cuesta 1998; Fernández 2010). Todo ello lleva Merluzzi (2007: 195) a afirmar que the 1568 Junta and its successive applications marked a turning point para la política de la monarquía en América.

El propio Toledo asistía a las reuniones de la junta, instancia que ya aprovechaba para dar cuenta de su opinión general respecto de las audiencias. Veía en ellas el culpable de la falta de autoridad que según 
él padecían los virreyes y le exigió a la Junta "que a mí no se me de menos que la que tenía el marqués de Cañete" (Merluzzi 2003: 49), quien había sido virrey entre 1556 y 1560 . Como señala Merluzzi (2003: 61), la junta se mostró de acuerdo con lo expuesto por el futuro virrey y que los conflictos "se puede con razón temer serán mayor adelante".

La figura clave de la Junta Magna fue el cardenal Espinosa, a su vez el patrón de Toledo en la corte de Felipe II (Mumford 2012: 75). Desde 1565, Espinosa era presidente del Consejo de Castilla y una de sus principales herramientas de gobierno era la colocación de personas de su confianza en los distintos territorios de la monarquía, tales como el duque de Alba en los Países Bajos o Luis de Requesens y Juan de Zúñiga en Italia (Martínez Millán 2017: 116). En aquel momento la corte de Felipe II estaba dividida en principalmente dos facciones, los llamados albistas y ebolistas (Martínez Millán 2017). Las facciones se solían constituir por intereses comunes, relaciones de amistad y alianzas temporarias, todo con el fin de ejercer influencia sobre la política de la monarquía (Rodríguez Arrocha 2017: 81). La componente ideológica que une a partidos ${ }^{5}$ del mundo moderno, en cambio, era mucho menos importante en aquella época en comparación con los puntos arriba mencionados.

Aunque se solía considerar a Espinosa como parte de la facción ebolista (Maltby 1985: 99), como señala Martínez Millán (1992: 181), dicha afirmación no cuenta con evidencia y se comprueba más bien que hubo fuertes desacuerdos entre Espinosa y el príncipe de Éboli, líder de la facción ebolista, especialmente en temas de hacienda.

Si bien esto no significa que Espinosa perteneciera a la facción albista, sí tuvo una gran cercanía con el duque de Alba (Martínez Millán 2017: 114) y desde la ausencia de este de la corte por la rebelión de los Países Bajos (1567) es Espinosa quien mayor influencia ejercía sobre Felipe II en la corte (Borgognoni 2017). Vale la pena en este momento señalar que la familia de Francisco de Toledo (los condes de Oropesa) y la del duque de Alba eran dos ramas de la misma estirpe de los Toledo. De hecho, el título de conde de Oropesa se creó en 1475 precisamente para una línea segundona de los duques de Alba (Soria Mesa 2007: 70, ver también Vidal de Barnola 1998).

En 1571 se dio otro factor más a favor de Francisco de Toledo cuando Juan de Ovando fue nombrado presidente del Consejo de Indias. Ovando y Toledo también eran muy cercanos y Ovando junto con Espinosa fue responsable del nombramiento del virrey Toledo (Ugarte del Pino 2002). Espinosa y Ovando juntos hicieron posible el nombramiento de Toledo sin la intervención del Consejo de Indias (Levillier 1935: 81). Con Ovando como presidente del consejo el peso de los pareceres del virrey Toledo probablemente tuvieron el aumento decisivo para que se atendieran sus solicitudes. Esta afirmación gana todavía más peso al considerar que Ovando rápidamente llegó a dominar el Consejo, hasta tal punto que Poole (2004: 158) afirma que entre 1571 y 1575 "Juan de Ovando was ${ }^{6}$ the Council of the Indies".

Ciertamente, con la muerte de Espinosa en 1572, la caída en desgracia de Alba y la muerte del príncipe de Éboli (1573), toda la dinámica de influencias en la corte iba a cambiar y también el peso del virrey Toledo disminuiría en este contexto (Merluzzi 2003: 246). Esto, sin embargo, no es inmediato y para los años iniciales de su virreinato, en los que cae también la supresión de la Audiencia de Concepción, su peso e influencia en la corte fueron considerables, gracias al cardenal Espinosa y a Juan de Ovando quien moriría en 1575. A eso hay que añadir que durante la primera parte del reinado de Felipe II, hasta 1580 aproximadamente, el rey confía más en la habilidad de sus representantes de valorar la situación in situ, lo que también solía incorporar en las instrucciones ("vos que estáis presente"). Solo después Felipe II creía tener toda la información y ser él solo capaz de tomar las decisiones definitivas (Parker 2014: 300-301).

\section{Conclusión}

Habitualmente se ha destacado la importancia del licenciado Castro para la creación de la Audiencia de Concepción y a la vez se ha tenido en poca consideración al virrey Toledo para su supresión. Nuestra conclusión es que fue justamente al revés. Cuando el licenciado Castro envía su parecer favorable en varias ocasiones durante 1565 , la decisión parece ya haber sido tomada, porque en enero de dicho año se nombraron oidores para la futura audiencia de Chile.

A pesar de que hubo muchas voces pidiendo la supresión de la audiencia por su ineficiencia que no correspondía a los gastos que producía, concluimos que fueron las cartas del virrey Toledo las que hicieron que en la corte se tomara la decisión de 
suprimirla. Ya en los años 1570 y 1571 el virrey insiste en este sentido, pero sería en 1572 cuando con más énfasis se pronuncia a favor de suprimir la Audiencia de Concepción.

Para entender la importancia que tenía el parecer de Toledo, es necesario tomar en cuenta su posición y su apoyo en la corte de Felipe II. Primero, está la figura del cardenal Espinosa, patrón de Toledo en la corte y figura clave de la Junta Magna, la que termina denominando a Toledo para el gobierno del Perú. Con la caída en desgracia del príncipe de Éboli y la ausencia del duque de Alba por la revuelta en los Países Bajos es Espinosa quien ejerció principalmente su influencia en la corte.

La influencia de Toledo en la corte se consolida aún más en 1571 cuando Juan de Ovando asciende a la presidencia del Consejo de Indias, órgano clave para todas las decisiones que se toman acerca de los territorio americanos y hasta 1575 completamente controlado por él, a quien también caracteriza una gran cercanía con Francisco de Toledo y junto con Espinosa ya había sido clave para su nombramiento en 1568.

La influencia combinada de Espinosa (si bien este muere en septiembre del 1572) y Ovando creemos que termina siendo el factor clave para que en la corte se tomen en cuenta las sucesivas cartas que manda el virrey para la supresión de la Audiencia de Concepción. Sería solo en los años sucesivos que la posición de Toledo en la corte se debilita, especialmente tras la muerte de Ovando en 1575. Con ello no olvidamos que se pidió también desde otros ámbitos la supresión de la Audiencia de Concepción, por lo que hay varios factores que confluyen a ello, sin embargo, por lo expuesto creemos poder afirmar que el virrey Toledo constituye el factor clave para que se tomara tal decisión.

\section{Referencias Citadas}

Abril Stoffels, R.

1996 Junta Magna de 1568, resoluciones e instrucciones (fundación de la inquisición limeña. En Francisco de la Cruz. Inquisición. Actas II, 1. Del mito bíblico a la utopía indiana (papa emperador de Israel y de las Indias y del universo mundo?), editado por Miguel Abril Stoffels y Vidal Abril Castelló, pp. 196-227. Editorial CSIC. Madrid. Academia Chilena de la Historia

1992 Real Audiencia de Concepción 1565-1573. Documentos para su estudio. Banco de Concepción. Concepción.

Amunátegui, M.

1890 El cabildo de Santiago desde 1573 hasta 1581. Tomo I. Imprenta Nacional. Santiago de Chile.

Angeli, $S$

2004 "No a habido causa de gobierno ni justicia que yo haya contradicho": cargos y descargos del doctor Bravo de Saravia ante la visita a la Audiencia de Lima (1561-1563). Revista de Historia del Derecho. Sección Investigaciones 47: 13-31.

Arvizu Galarraga, F.

1986 El fiscal de la Audiencia en Indias y su paralelo castellano (siglos XVI y XVII). En Poder y presión fiscal en la América española (siglos XVI, XVII y XVIII), editado por la Universidad de Valladolid, pp. 203-233. Universidad de Valladolid, Valladolid.

Barrientos Grandón, J.

1990 La apelación en materia de gobierno y su aplicación en la Real Audiencia de Chile (siglos XVII, XVIII, XIX). Revista Chilena de Historia del Derecho 16: 343-382.

Barrientos Grandón, J.

1992 La cultura jurídica en el reino de Chile. Bibliotecas y ministros de la Real Audiencia de Santiago de Chile (s. XVII-XVIII). Escuela de Derecho de la Universidad Diego Portales, Santiago de Chile.
Barrientos Grandón, J.

1993 "La Real Audiencia de Concepción (1565-1575)". Revista de Estudios Histórico-Jurídicos 15: 131-178.

Barrientos Grandón, J.

2000 La Real Audiencia de Chile. La institución y sus hombres 1605-1817. Fundación Histórica Tavera. Madrid.

Barrientos Grandón, J.

2003 "La creación de la Real Audiencia de Santiago de Chile y sus ministros fundadores. Sobre la formación de familias en la judicatura chilena". Revista de Estudios HistóricoJurídicos 25: 233-338.

Barrios, F.

2004 El gobierno de un mundo. Virreinatos y audiencias en la América Hispánica. Ediciones de la Universidad de Castilla-La Mancha, Cuenca.

Bermúdez, A.

1976 "Las funciones del presidente en la Audiencia de Indias". En Memoria del IV Congreso Internacional de Historia del Derecho Indiano, editado por la Universidad Nacional Autónoma de México, pp. 85-96. Universidad Nacional Autónoma de México, Ciudad de México.

Borgognoni, E.

2017 "Confesionalismo, gobierno y privanza. El cardenal Diego de Espinosa (1565-1572)”. Chronica Nova 43: 169-186.

Dougnac Rodríguez, A.

2004 "Las Audiencias Indianas y su transplante desde la metrópoli”. En El gobierno de un mundo. Virreinatos y audiencias en la América Hispánica, editado por Feliciano Barrios, pp. 539-586. Ediciones de la Universidad de Castilla-La Mancha, Cuenca.

Fernández, R.

2010 "La visita al Consejo de Indias de Juan de Ovando y la Nueva España”. Revista Chilena de Historia del Derecho 22: $445-457$. 
Ferrando Keun, R

2012 [1986] Y así nació la frontera...conquista, guerra, ocupación, pacificación 1550-1900. Ediciones Universidad Católica de Temuco. Temuco.

García Gallo, A.

1975 "Las Audiencias Indianas: su origen y caracteres". En Memoria del Segundo Congreso Venezolano de Historia, editado por la Academia Nacional de la Historia, pp. 359432. Academia Nacional de la Historia, Caracas.

Garriga, C.

1994 LaAudiencia y las Chancillerías castellanas (1371-1525). Historia política, régimen jurídico y práctica institucional. Centro de Estudios Constitucionales, Madrid.

Garriga, C.

2004 Las Audiencias: justicia y gobierno de las Indias. En El gobierno de un mundo. Virreinatos y audiencias en la América Hispánica, editado por Feliciano Barrios, pp. 711794. Ediciones de la Universidad de Castilla-La Mancha, Cuenca.

Gómez Rivas, L.

1990 El virrey del Perú don Francisco de Toledo: antecedentes socio-políticos de su labor de gobierno. Universidad Complutense. Madrid. Tesis de doctorado inédita.

Góngora, $\mathrm{M}$.

1951 El estado en el derecho indiano. Época de fundación 1492-1570. Universidad de Chile. Santiago de Chile.

González Cuerva, G. y Koller, A.

2017. Photography of a ghost: Factions in early modern Courts. En A Europe of courts, a Europe of factions. Political groups at Early Modern centres of power (1550-1700), editado por Rubén González Cuerva y Alexander Koller, pp. 1-19. Brill. Leiden.

González Echenique, J.

1992 "Prólogo". En Real Audiencia de Concepción 15651573. Documentos para su estudio, editado por la Academia Chilena de la Historia, pp. 9-19. Banco de Concepción. Concepción.

Hera Pérez-Cuesta, A.

1998 "Consolidación de las instituciones americanas bajo Felipe II y Juan de Ovando". En Las sociedades ibéricas y el mar a finales del siglo XVI. Vol. 6 Las Indias, editado por Luis Antonio Ribot García y Ernest Belenguer Cebrià, pp. 121-137. Sociedad Estatal Lisboa '98. Lisboa.

Hernández Sánchez-Barba, M.

1992 Castilla y América. Mapfre. Madrid.

Huneeus Pérez, A.

1956 Historia de las polémicas de Indias en Chile durante el siglo XVI, 1536-1598. Editorial Jurídica de Chile. Santiago de Chile.

Levillier, R.

1918 La Audiencia de Charcas. Correspondencia de presidentes y oidores. Tomo 1. J. Pueyo. Madrid.

Levillier, R.

1920 Francisco de Aguirre y los orígenes del Tucumán, 1550-1570. Imprenta de Juan Pueyo. Madrid.

Levillier, R.

1921 Gobernantes del Perú, Cartas y papeles, Siglo XVI, Tomo III. Sucesores de Rivadeneyra. Madrid.

Levillier, R.

1924 Gobernantes del Perú, Cartas y papeles, Siglo XVI, Tomo IV. Imprenta de Juan Pueyo. Madrid.
Levillier, R.

1935 Don Francisco de Toledo. Supremo organizador del Perú: su vida, su obra (1515-1582). Colección de Publicaciones Históricas de la Biblioteca del Congreso. Madrid.

Maltby, W.

1985 El Gran Duque de Alba. Un siglo de España y Europa, 1507-1582. Ediciones Turner. Madrid.

Martínez Millán.

1992 "Grupos de poder en la corte durante el reinado de Felipe II: la facción ebolista, 1554-1573". En Instituciones y élites de poder en la monarquía hispana durante el siglo XVI, editado por José Martínez Millán, pp. 137-198. Universidad Autónoma de Madrid. Madrid.

Martínez Millán, J.

2017 Factions and political groups at Philipp II's Court: Albists vs Ebolists. En A Europe of courts, a Europe of factions. Political groups at Early Modern centres of power (1550-1700), editado por Rubén González Cuerva y Alexander Koller, pp. 109-129. Brill. Leiden.

Martiré, E.

1997 "La Audiencia de Concepción en Chile (1565-1573), un caso de Audiencia con expresas funciones de gobierno". Anuario de historia del derecho español 67: 1381-1400.

Mazzei de Grazia, L.

1989 "Fundación y supresión de la primera audiencia de Chile: Concepción (1567-1575)". Revista de Indias 49: 27-89.

Merluzzi, M.

2003. Politica e governo nel Nuovo Mondo. Francisco de Toledo viceré del Perù (1569-1581). Carocci editore. Roma.

Merluzzi, M.

2007 "Religion and State Policies in the Age of Philip II: the 1568 Junta Magna of the Indies and the New Political Guidelines for the Spanish American Colonies". En Religion and power in Europe: conflict and convergence, editado por Joaquim Carvalho, pp. 183-201. Plus-Pisa University Press. Pisa.

Merluzzi, M.

2012 "Los virreyes y el gobierno de las Indias. Las instrucciones al primer virrey de Nueva España (siglo XVI)". En El mundo de los virreyes en las monarquías de España y Portugal, editado por Pedro Cardim y Joan-Lluís Palos, pp. 203-245. Iberoamericana, Madrid.

Mumford, J.

2012 Vertical empire. The general resettlement of Indians in the colonial Andes. Duke University Press. Durham.

Muñoz Feliú, R.

1937 La real audiencia de Chile. Escuela tipográfica "La gratitud nacional". Santiago de Chile.

Parker, G.

1998 The Grand Strategy of Philipp II. Yale University Press. New Haven.

Parker, G.

2014 Imprudent king. A new life of Philip II. Yale University Press. New Haven.

Pietschmann, $\mathrm{H}$.

1980 Die staatliche Organisation des kolonialen Iberoamerika. Klett-Cotta. Stuttgart.

Poole, S.

2004 Governing the Spanish empire in the reign of Philip II. University of Oklahoma Press. Norman. 
Puente Brunke, J.

2004 "Las Audiencias en Indias y sus ministros: vigencia social y aspiraciones (a propósito de un oidor del siglo XVII)". En El gobierno de un mundo. Virreinatos y audiencias en la América Hispánica, editado por Feliciano Barrios, pp. 587-599. Ediciones de la Universidad de Castilla-La Mancha, Cuenca.

Ramos, D.

1986 "La crisis indiana y la Junta Magna de 1568". Jahrbuch für Geschichte Lateinamerikas 23 (1): 1-62.

Reig Satorres, J.

1972 "Reales Audiencias". En Anuario Histórico Jurídico Ecuatoriano 2: 525-614.

Rivero Rodríguez, M.

2011 La edad de oro de los virreyes. El virreinato en la monarquía hispánica durante los siglos XVI y XVII. Akal. Madrid.

Rodríguez Arrocha, B.

2017 "Los intereses creados en la justicia de la Edad Moderna". En Imperial. Il ruolo della rappresentaza politica informale nella costruzione e nello sviluppo delle entità statuali $(X V$ XXI secolo), editado por Giuseppe Ambrosino y Loris de Nardi, pp. 81-100. Qui Edit. Bolzano.

Salles, E. y H. Noejovich.

2008 La visita general y el proyecto de gobernabilidad del virrey Toledo. Dos tomos. Universidad de San Martín de Porres. Lima.

Salvat Monguillot, M.

1973 "Las funciones de gobierno de la audiencia de Chile". En III Congreso del Instituto Internacional de Historia del Derecho Indiano, editado por el Instituto Nacional de Estudios Jurídicos, pp. 597-622. Instituto Nacional de Estudios Jurídicos. Madrid.
Sánchez, C.

1996 Las Indias en la Monarquía Católica. Universidad de Valladolid. Valladolid.

Soria Mesa, E.

2007 La nobleza en la España moderna. Cambio y continuidad. Marcial Pons, Madrid.

Suárez, S.

1989 Las Reales Audiencias Indianas. Fuentes y bibliografía. Academia Nacional de la Historia, Caracas.

Tantaleán Arbulú, J.

2012 El virrey Francisco de Toledo y su tiempo. Proyecto de gobernabilidad, el imperio hispano, la plata peruana en la economía-mundo y el mercado colonial. Dos tomos. Universidad de San Martín de Porres. Lima.

Toribio Medina, J.

1956 Colección de Documentos Inéditos para la Historia de Chile. Tomo I, 1558-1572. Fondo Histórico y Bibliográfico J.T. Medina. Santiago de Chile.

Toribio Medina, J.

1957 Colección de Documentos Inéditos para la Historia de Chile. Tomo II, 1573-1580. Fondo Histórico y Bibliográfico J.T. Medina. Santiago de Chile.

Ugarte del Pino, J.

2002 "El Perú en tiempos de Felipe II: la relación OvandoToledo". En Derecho y administración pública en las Indias hispánicas, editado por Feliciano Barrios, pp. 1775-1784. Universidad de Castilla-La Mancha. Madrid.

Vidal de Barnola, L.

1998 "Los títulos nobiliarios concedidos a los Álvarez de Toledo”. En Los Álvarez de Toledo. Nobleza viva, editado por María del Pilar García Pinacho, pp. 53-89. Junta de Castilla y León. Valladolid.

\section{Notas}

1 El presente trabajo es producto del Proyecto Fondecyt de Iniciación $N^{\circ} 11190354$, Conicyt, Chile.

2 La decisión de crear la Audiencia de Concepción se tomó ya en 1565, sin embargo, no entró en funciones hasta 1567, por ello suelen aparecer ambas fechas en los estudios. Lo mismo ocurre con la supresión que se decreta en 1573 pero la disolución se produce solamente en 1575 .

3 Castro fue nombrado en agosto de 1563, sin embargo, no llegaría a Lima hasta septiembre de 1564.

4 Solo como ejemplo de los virreinatos bajo Carlos V se pueden referir los casos de Juan III de Lanuza (1520-1535) en Aragón, Pedro Álvarez de Toledo y Zúñiga (1532-1555) en Nápoles o Antonio de Mendoza en Nueva España (1535-1550).

5 Como señalan Cuerva y Koller (2017: 2-3), los términos "facción" y "partido" suelen ser intercambiables para la Edad Moderna, sin embargo, concordamos con dichos autores que es preferible usar "facción", debido a que es el término que suele aparecer en los documentos.

6 La cursiva es del autor Poole. 